\title{
Detection of Canine Vector-Borne Filariasis and Their Wolbachia Endosymbionts in French Guiana
}

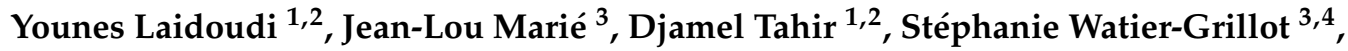 \\ Oleg Mediannikov 1,2 ${ }^{1 D}$ and Bernard Davoust 1,2,3,* \\ 1 Aix Marseille Univ., IRD, AP-HM, MEPHI, IHU-Méditerranée Infection, 13385 Marseille, France; \\ younes.laidoudi@yahoo.com (Y.L.); djamel.tahir@yahoo.fr (D.T.); olegusss1@gmail.com (O.M.) \\ 2 IHU Méditerranée Infection, 13385 Marseille, France \\ 3 Animal Epidemiology Working Group of the Military Health Service, 13014 Marseille, France; \\ jean-lou.marie@wanadoo.fr (J.-L.M.); s.watier.grillot@gmail.com (S.W.-G.) \\ 4 Epidemiology and Public Health Center of the French Armed Forces, 13014 Marseille, France \\ * Correspondence: bernard.davoust@gmail.com; Tel.: +33-4-13-73-24-01
}

Received: 10 April 2020; Accepted: 18 May 2020; Published: 21 May 2020

\begin{abstract}
In French Guiana, canine heartworm disease is well known, but the diversity of filarial parasites of dogs remains largely unknown. A total of 98 canine blood samples from Cayenne and Kourou were assessed by a blood wet mount preparation, heartworm antigen test and molecular exploration of filarioid and Wolbachia DNAs, followed by a multiplex species-specific qPCR's identification and a subsequent sequencing analysis. Thereafter, a phylogeny based on maximum likelihood was carried out to facilitate specific identification. Five dogs were microfilaremic. Heartworm antigens were detected in $15(15.3 \%)$ dogs. Of these, six $(6.1 \%)$ were considered as occult infections as neither microfilariae nor Dirofilaria immitis DNA were detected. The $11(11.2 \%)$ $D$. immitis isolates corresponded to a low virulent strain. Six of the D. immitis isolates were positive for Wolbachia endosymbionts of $D$. immitis belonging to the clade C DNA. Acanthocheilonema reconditum DNA was detected in $3(3.1 \%)$ samples. Of these latter, one was found co-infected with the Brugia sp. genotype and the DNA of the clade D of the Wolbachia endosymbiont of Brugia species. This latter was also detected in two filarioid DNA-free samples. Finally, two samples were positive for Cercopithifilaria bainae genotype, which is distinct from those identified in Europe. The present study highlights the urgent need to implement chemoprophylaxis associated with anti-Wolbachia drugs to control these potential zoonoses.
\end{abstract}

Keywords: canine vector-borne helminth; filariasis; Wolbachia; species diversity; zoonosis; French Guiana

\section{Introduction}

Canine vector-borne diseases (CVBDs) constitute a worldwide group of illnesses affecting dogs. They are caused by a wide range of bacteria, viruses, protozoa and helminths, all transmitted to dogs by parasitic arthropods bites [1]. These diseases constitute an important public health concern in tropical and subtropical regions from the Old and New World, where they are endemic [2]. In French Guiana, dogs seem to be affected by several major CVBDs, such as leishmaniasis [3], anaplasmosis [4], trypanosomiasis [5], ehrlichiosis [6] and arbovirosis [7].

Canine filariasis are a group of canine vector-borne helminth (CVBH) caused by several nematodes belonging to the Onchocercidae family. Canids constitute suitable hosts for many filarial parasites of veterinary and human importance, such as the zoonotic Dirofilaria immitis (Leidy 1856), the agent of cardiopulmonary dirofilariasis (also known as heartworm) in dogs and pulmonary dirofilariasis in human [8], D. repens which causes in humans, like in dogs the subcutaneous filariasis [9]. These two 
species, together with brugian parasites that cause lymphatic filariasis (e.g., Brugia timori, B. malayi and $B$. pahangi) $[10,11]$, constitute the most thread-like filarial worms causing millions of canine and human cases throughout the world [12-14]. These parasites have bloodstream microfilariae and are transmitted by mosquito bites. Dogs may also be affected with another less or completely avirulent group of CVBH transmitted by parasitic arthropods other than mosquitoes, such as Acanthocheilonema reconditum and Cercopithifilaria spp. parasite of the sub-cutaneous connective tissues which are actively transmitted through the bites of fleas/lice and ticks, respectively [15-18]. Furthermore, A. dracunculoides infests the peritoneal cavity of dogs [19] and a little known filarioid Onchocerca lupi inducing ocular nodules on the eyelids, conjunctiva and sclera in dogs as in human [20].

Some filarioids of the subfamilies Onchocercinae and Dirofilariinae are associated with an endosymbiotic intracellular bacterium of the genus Wolbachia [21], which can be found in all filarioid developmental stages and is essential for the long-term survival of the adult filarioids [22]. Moreover, Wolbachia are host-specific, and each filarial species that harbor Wolbachia is associated with a specific bacterial genotype [23]. These features constitute make its a suitable target for the diagnosis of filarial infection, especially when occurring in dead-end hosts as is the case of D. immitis in humans and cats [24,25]. Recent studies showed that the combined detection of Wolbachia and filarioid DNA improves the diagnosis of these infections $[26,27]$.

$\mathrm{CVBH}$ are strongly related to the distribution of their vectors and are therefore geographically varied. Few studies data are available on canine filariasis from Latin America. The current species reported from canids in Brazil are potentially zoonotic and are often caused by A. reconditum, C. bainae, D. grassii, D. immitis and D. repens [28]. In addition, two cases of human filariasis have been reported across the continent, caused by lymphatic filariasis in Brazil, Dominican Republic, Guyana and Haiti and onchocerciasis in Brazil, Colombia, Ecuador, Guatemala, Mexico and Venezuela [29]. However, the information on $\mathrm{CVBH}$ in French Guiana is very scarce.

In the present study, we aimed to determine the presence of $\mathrm{CVBH}$ in dog blood samples from French Guiana as well as the strains of their endosymbiotic Wolbachia using molecular assays. Also aimed to investigating $D$. immitis infection rate using heartworm antigen test. The study provides preliminary information that could use in the future for the control of the potentially zoonotic filariasis in dogs from French Guiana.

\section{Materials and Methods}

\subsection{Sampling and Study Area}

In January 2016, in two sites of French Guiana separated by 60 km, 67 adult dogs, including 18 stray dogs and 49 shelter dogs were sampled in Cayenne $\left(4^{\circ} 56^{\prime} 4.6^{\prime \prime} \mathrm{N}, 52^{\circ} 19^{\prime} 49.19^{\prime \prime} \mathrm{W}\right)$, the main city of French Guiana with 57,000 residents and 31 adult shelter dogs from Kourou (5 $9^{\prime} 34.92^{\prime \prime}$ N, $\left.52^{\circ} 39^{\prime} 1.08^{\prime \prime} \mathrm{W}\right)$. All dogs were subjected to a blood sampling via a cephalic venipuncture using a BD Vacutainer ${ }^{\mathrm{TM}}$ K3EDTA tubes (Fisher Scientific, Illkirch, France), then conditioned at $4{ }^{\circ} \mathrm{C}$ and transported to our laboratory. Ethical aspects related to dog sampling were treated in accordance with the French law. Owner consent was obtained for all shelter dogs of both cities. Likewise, the consent of the director of the Cayenne dog pound was obtained for all stray dogs. All dogs $(n=98)$ were apparently healthy, including 52 females and 46 males.

\subsection{Ethics Approval}

Dogs were examined by veterinarians with the assistance and acceptance of their owners. Ethical aspects related to dog sampling were treated in accordance with the French law. The owner consents were obtained for all shelter dogs of both cities. Likewise, the consent of the director of the Cayenne dog pound was obtained for all stray dogs. 


\subsection{Microfilaria and Heartworm Antigen Tests}

Immediately after sampling, the dog's blood samples were processed for the detection of heartworm antigens using the WITNESS ${ }^{\circledR}$ Dirofilaria (Zoetis, Lyon, France). According to the manufacturer's recommendations, this immunochromatographic test allowed the identification of heartworm antigens from bloodstream. The blood wet mount preparation was also performed on each blood sample for microfilariae detection. One drop of homogenized EDTA blood was examined under a microscope at low magnification. Microfilaria-positive samples were confirmed by the visualization of live microfilariae moving like snakes between blood cells. In the present study, samples with D. immitis antigen-positive, but negative in PCR were considered as heartworm occult infection.

\subsection{DNA Extraction}

Genomic DNA was extracted individually from all blood samples. The detail of the extraction protocol is described elsewhere [9]. Briefly, DNAs were obtained after two lysis steps using a powder glass and proteinase $\mathrm{K}$ for the mechanical and enzymatic digestion, respectively. The extraction was carried out in Biorobot EZ1 System with the EZ1 DNA tissue kit (Qiagen, Courtaboeuf, France) following the manufacturer's instructions. Each extraction was eluted in a total volume of $100 \mu \mathrm{L}$ and stored at $-20^{\circ} \mathrm{C}$ until analysis.

\subsection{Molecular Screening for Filarioid and Wolbachia DNAs}

First, all samples were tested using the combined multiplex approach, recently developed for the detection of filarioid and Wolbachia DNAs [27]. The screening was processed as follows: (i) the exploration of filarial and Wolbachia DNAs using, respectively, the pan-filarial [Pan-Fil 28S] and the pan-Wolbachia [All-Wol-16S] qPCRs (Table 1), (ii) followed by species specific identification from samples tested positive for filarioid-Wolbachia DNAs using, respectively, the triplex [Triplex TaqMan COI] qPCR targeting D. immitis, D. repens and A. reconditum and the duplex [Wol-Diro ftsZ] qPCR targeting the prokaryotic homolog of the eukaryotic protein tubulin gene (ftsZ) of Wolbachia of $D$. immitis and that of $D$. repens (Table 1 ). 
Table 1. Primers and probes used in this study.

\begin{tabular}{|c|c|c|c|c|c|c|c|c|}
\hline Application & $\begin{array}{l}\text { System } \\
\text { Name's }\end{array}$ & Target Gene & $\begin{array}{c}\text { Primer \& } \\
\text { Probes Name's }\end{array}$ & Sequences $5^{\prime}-3^{\prime}$ & $\begin{array}{l}\text { Amplicon } \\
\text { Size (pb) }\end{array}$ & $\begin{array}{c}\text { Tm/Elongation } \\
\text { Time }\end{array}$ & Specificity & References \\
\hline \multirow{4}{*}{ qPCR } & Pan-Fil 28S & 28S LSU rRNA & $\begin{array}{l}\text { qFil-28S-F } \\
\text { qFil-28S-R } \\
\text { qFil-28S-P }\end{array}$ & $\begin{array}{c}\text { TTGTTTGAGATTGCAGCCCA } \\
\text { GTTTCCATCTCAGCGGTTTC } \\
\text { 6FAM-5'-CAAGTACCGTGAGGGAAAGT-3'-TAMRA }\end{array}$ & 151 & $60^{\circ} \mathrm{C} / 30^{\prime \prime}$ & Filarial species & \multirow{4}{*}{ [27] } \\
\hline & All-Wol-16S & 16S rRNA gene & $\begin{array}{l}\text { all.Wol.16S.301-F } \\
\text { all.Wol.16S.478-R } \\
\text { all.Wol.16S.347-P }\end{array}$ & $\begin{array}{c}\text { TGGAACTGAGATACGGTCCAG } \\
\text { GCACGGAGTTAGCCAGGACT } \\
\text { 6FAM-5'-AATATTGGACAATGGGCGAA-3'-TAMRA }\end{array}$ & 177 & $60^{\circ} \mathrm{C} / 30^{\prime \prime}$ & Wolbachia sp. & \\
\hline & $\begin{array}{c}\text { Triplex } \\
\text { TaqMan COI }\end{array}$ & $\cos 1$ & $\begin{array}{l}\text { Fil.COI.749-F } \\
\text { Fil.COI.914-R } \\
\text { D.imm.COI.777-P } \\
\text { D.rep.COI.871-P } \\
\text { A.rec.COI.866-P }\end{array}$ & $\begin{array}{c}\text { CATCCTGAGGTTTATGTTATTATTTT } \\
\text { CWGTATACATATGATGRCCYCA } \\
\text { 6FAM-CGGTGTTTGGGATTGTTAGTG-TAMRA } \\
\text { 6VIC-TGCTGTTTTAGGTACTTCTGTTTGAG-TAMRA } \\
\text { Cy5-TGAATTGCTGTACTGGGAACT-BHQ-3 }\end{array}$ & 166 & $60^{\circ} \mathrm{C} / 30^{\prime \prime}$ & $\begin{array}{l}\text { FAM: } D \text {. immitis } \\
\text { VIC: } D \text {. repens } \\
\text { Cy5: } A \text {. } \\
\text { reconditum }\end{array}$ & \\
\hline & Wol-Diro ftsZ & $\begin{array}{l}\text { Prokaryotic } \\
\text { homolog of the } \\
\text { eukaryotic } \\
\text { protein tubulin }\end{array}$ & $\begin{array}{l}\text { WDiro.ftsZ.490-F } \\
\text { WDiro.ftsZ.600-R } \\
\text { WDimm.ftsZ.523-P } \\
\text { WDrep.ftsZ.525-P }\end{array}$ & $\begin{array}{c}\text { AAGCCATTTRGCTTYGAAGGTG } \\
\text { AAACAAGTTTTGRTTGGAATAACAAT } \\
\text { 6FAM-CGTATTGCAGAGCTCGGATTA-TAMRA } \\
\text { 6VIC-CATTGCAGAACTGGGACTGG-TAMRA }\end{array}$ & 111 & $60^{\circ} \mathrm{C} / 30^{\prime \prime}$ & $\begin{array}{l}\text { FAM: Wolbachia } \\
\text { of } D \text {. immitis } \\
\text { VIC: Wolbachia } \\
\text { of D. repens }\end{array}$ & \\
\hline \multirow{4}{*}{ PCR } & 16S W-Spec & 16S rRNA & $\begin{array}{l}\text { W-Specf } \\
\text { W-Specr }\end{array}$ & $\begin{array}{l}\text { CATACC TATTCGAAGGGATAG } \\
\text { AGCTTCGAGTGAA ACCAATTC }\end{array}$ & 438 & $60^{\circ} \mathrm{C} / 1^{\prime}$ & Wolbachia sp. & [30] \\
\hline & Pan-Nem 18S & 18S SSU rRNA & $\begin{array}{l}\text { Fwd.18S.631 } \\
\text { Rwd.18S.1825r }\end{array}$ & $\begin{array}{c}\text { TCGTCATTGCTGCGGTTAAA } \\
\text { GGTTCAAGCCACTGCGATTAA }\end{array}$ & 1127-1155 & $54^{\circ} \mathrm{C} / 1^{\prime} 30^{\prime \prime}$ & Nematodes & [9] \\
\hline & Pan-Fil cox 1 & $\operatorname{cox} 1$ & $\begin{array}{l}\text { Fwd.957 } \\
\text { Rwd.1465 }\end{array}$ & $\begin{array}{l}\text { ATRGTTTATCAGTCTTTTTTTATTGG } \\
\text { GCAATYCAAATAGAAGCAAAAGT }\end{array}$ & 509 & $52^{\circ} \mathrm{C} / 45^{\prime \prime}$ & Filarial species & [27] \\
\hline & Pan-Fil 12S & $12 \mathrm{~S}$ rRNA & $\begin{array}{l}\text { Fwd.12S.110 } \\
\text { Rwd.12S.681 } \\
\end{array}$ & $\begin{array}{l}\text { TCCAGAATAATCGGCTATACATTTT } \\
\text { CCATTGACGGATGGTTTGTA }\end{array}$ & 497 to 570 & $56^{\circ} \mathrm{C} / 45^{\prime \prime}$ & Filarial species & $\begin{array}{l}\text { The present } \\
\text { study }\end{array}$ \\
\hline
\end{tabular}




\subsection{Molecular and Phylogenetic Characterization of Filarioid and Wolbachia}

First, all samples that tested positive for filarial DNA were subjected to PCR amplification and sequencing analysis using the following systems: The standard (Pan-Nematoda) PCR [9] was used to amplify $1194 \mathrm{pb}$ from the small subunit rRNA gene and the filarial specific (Pan-fil COI) PCR [27] targeting 509 pb from the Cytochrome c oxidase subunit I (cox1) gene. The third PCR was developed to amplify 497-570 pb from the 12S rDNA gene of filarial nematodes (Table 1), while all Wolbachia-positive samples were tested using the standard (W16S-Spec) PCR [30] targeting 438 pb fragment from the $16 S$ rDNA.

When the filarial co-infections were found, we performed a serial 2-fold dilution of blood using Hank's balanced salt solution (GIBCO $\left.{ }^{\circledR}\right)$ followed by a DNA extraction as described above. This was performed in duplicate. The objective was to concentrate only one species of microfilariae before the extraction. Once, the DNA were obtained from each dilution they were processed for amplification using the 18S, cox 1 and 12S PCR primers, then the last two positive dilution by each PCR were subjected to the sequencing analysis.

All PCR reactions were carried out in a total volume of $50 \mu \mathrm{L}$, consisting of $25 \mu \mathrm{L}$ of AmpliTaq Gold master mix (Thermo Fisher Scientific, Waltham, MA, USA), $18 \mu \mathrm{L}$ of ultra-purified water DNAse-RNAse free, $1 \mu \mathrm{L}$ of each primer and $5 \mu \mathrm{L}$ of genomic DNA. PCR reactions with all systems were run using the following protocol: incubation step at $95^{\circ} \mathrm{C}$ for $15 \mathrm{~min}, 40$ cycles of one minute at $95{ }^{\circ} \mathrm{C}, 30 \mathrm{~s}$ for the annealing at a different annealing temperature for each PCR assay and elongation from $45 \mathrm{~s}$ to $1 \mathrm{~min}$ and $30 \mathrm{~s}$ (Table 1 ) at $72{ }^{\circ} \mathrm{C}$ with a final extension for five minutes at $72{ }^{\circ} \mathrm{C}$. PCR reactions were performed in a Peltier PTC-200 model thermal cycler (MJ Research, Inc., Watertown, MA, USA).

DNA amplicons generated through the PCRs were purified using filter-plate Millipore NucleoFast 96 PCR kit following the manufacturer's recommendations (Macherey Nagel, Düren, Germany). Purified DNAs were subjected to the second reaction using the BigDye ${ }^{\circledR}$ Terminator v. 3.1 Cycle Sequencing Kit (Applied Biosystems, Foster City, CA, USA), then the products were purified on the Sephadex G-50 Superfine gel filtration resin prior sequencing on the ABI Prism 3130XL.

Nucleotide sequences were assembled and edited by ChromasPro 2.0.0. The absence of co-amplification of nuclear mitochondrial genes (numts) was verified as recommended [31]. In addition, the visual verification of sequence chromatograms ambiguities, indels and stop codons of the translated sequences were performed by Chromas Pro 2.0.0 software. Sequences amplified from the filarial 18S, cox 1 and 12S rDNA as well as the $16 \mathrm{~S}$ rDNA of Wolbachia were subjected separately to a preliminary analysis using Basic Local Alignment Search Tool (BLAST) [32].

Filarial (18S, cox1 and 12S) and Wolbachia (16S) sequences obtained in this study were aligned with the closely related sequences retrieved from GenBank or Worm databases [33]. The alignment was performed using the ClustalW application within Bioedit v. 7.2.5. software [34]. DNA sequences of the non-filarial nematodes Dracunculus medinensis (AY852268), Heliconema longissimum (GQ332423) and (NC 016127) were used as outgroups for the 18S, cox1 and 12S trees, respectively and Rickettsia sp. (AB795333) for the Wolbachia 16S phylogram. Finally, the best nucleotide substitution model was chosen according to the Akaike Information Criterion (AIC) option in MEGA6 [35]. Phylograms were generated using the maximum likelihood (ML) method based on Kimura 2-parameter (+G) model [36] for both the $18 \mathrm{~S}$ and the $16 \mathrm{~S}$ and General Time Reversible $(+\mathrm{G},+\mathrm{I})$ [37], Hasegawa-Kishino-Yano $5+\mathrm{G}$ ) models [38] for the cox 1 and $12 \mathrm{~S}$ phylograms, respectively. All phylograms were generated with 1000 bootstrap replicates using all sites of the sequences.

\section{Results}

The detailed results of the dogs tested positive by at least one assay (parasitological, serologic or molecular) are shown in Table 2. The blood wet mount preparation revealed the presence of microfilariae in $6(6.1 \%)$ samples. One of these dogs was a dangerous stray dog that had to be euthanized according to regulations. We performed the autopsy and reported 12 adult filariae $(D$. immitis) in the right ventricle (6 males and 6 females) (Figure 1). The heartworm antigen test detected $15(15.3 \%)$ positive 
samples. The molecular screening revealed the presence of at least one molecular marker of filarioid and Wolbachia in $19(19.4 \%)$ samples. Of these, 7 (7.1\%) samples tested positive for both Wolbachia and filarial DNAs, $9(9.2 \%)$ samples for filarial DNA only and 3 (3.1\%) for Wolbachia DNA only.

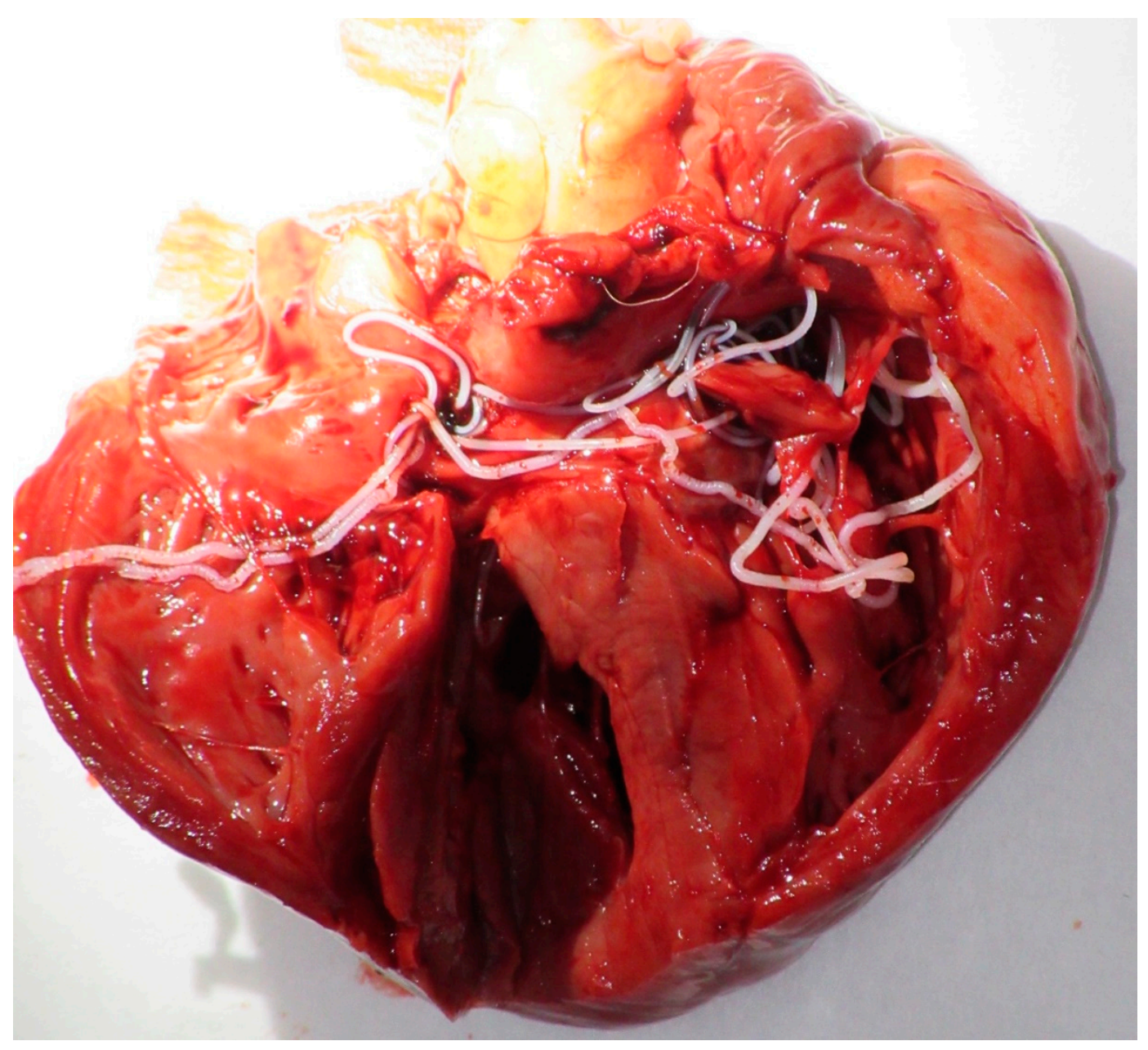

Figure 1. Heartworm (Dirofilaria immitis) in the canine heart of dog. 
Table 2. Results of dogs positive for at least one assays (parasitologic, serologic and molecular assays).

\begin{tabular}{|c|c|c|c|c|c|c|c|c|c|c|c|c|c|c|c|}
\hline \multirow{2}{*}{\multicolumn{2}{|c|}{$\begin{array}{c}\text { Sample } \\
\text { Description }\end{array}$}} & \multirow{4}{*}{$\begin{array}{c}\text { Parasitology } \\
\text { Thin } \\
\text { Smear }\end{array}$} & \multirow{4}{*}{$\begin{array}{c}\text { Serology } \\
\text { Witness } \\
\text { Dirofilaria }\end{array}$} & \multicolumn{7}{|c|}{ Filarioid } & \multicolumn{4}{|c|}{ Wolbachia } & \multirow{4}{*}{ Decision } \\
\hline & & & & \multicolumn{3}{|c|}{ qPCR-Based Detection } & \multicolumn{4}{|c|}{ Multi-Locus Genotyping } & \multicolumn{2}{|c|}{ qPCR-Based Detection } & \multicolumn{2}{|c|}{ 16S Genotyping } & \\
\hline \multirow{2}{*}{$\begin{array}{l}\text { Dog } \\
\text { Code }\end{array}$} & \multirow{2}{*}{ Location } & & & \multirow{2}{*}{$\begin{array}{l}\text { Filarial } \\
\text { DNA }\end{array}$} & \multirow{2}{*}{$\begin{array}{c}D . \\
\text { imm }\end{array}$} & \multirow{2}{*}{ A. rec } & \multicolumn{3}{|c|}{ Accession Number (AN) } & \multirow{2}{*}{ Species } & \multirow{2}{*}{ Wolbachia } & \multirow{2}{*}{ WDim } & \multirow{2}{*}{$\begin{array}{l}16 \mathrm{~S} \\
\text { (AN) }\end{array}$} & \multirow{2}{*}{$\begin{array}{l}\text { Wolbachia } \\
\text { Clade/Strains }\end{array}$} & \\
\hline & & & & & & & $18 \mathrm{~S}$ & $\operatorname{Cox} 1$ & $12 S$ & & & & & & \\
\hline CMT 01 & Cayenne & Neg. & Neg. & Pos. & N/A & Pos. & $\begin{array}{l}\text { MN795082 } \\
\text { MN795087 }\end{array}$ & $\begin{array}{l}\text { MT193075 } \\
\text { MT193074 }\end{array}$ & MT252011 & $\begin{array}{c}\text { A. reconditum } \\
\text { Brugia sp. }\end{array}$ & Pos. & N/A & MT231951 & $D / W B r$. & $\begin{array}{l}\text { A. reconditum } \\
\text { Brugia sp. }\end{array}$ \\
\hline CMT 12 & Cayenne & Neg. & Neg. & N/A & N/A & N/A & ..... & ..... & ..... & ..... & Pos. & N/A & MT231952 & $D / W B r$. & Brugia sp. \\
\hline CMT 13 & Cayenne & Neg. & Neg. & N/A & N/A & N/A & .... & .... &...- &.... & Pos. & N/A & MT231953 & $D / W B r$. & Brugia sp. \\
\hline CMT 14 & Cayenne & Neg. & Pos. & Pos. & $\mathrm{N} / \mathrm{A}$ & Pos. & MN795083 & MT193076 & MT252012 & A. reconditum & $\mathrm{N} / \mathrm{A}$ & N/A & .... & .... & $\begin{array}{l}\text { A. reconditum/ } \\
\text { O-Heartworm }\end{array}$ \\
\hline CMT 18 & Cayenne & Pos. & Neg. & Pos. & N/A & Pos. & MN795084 & MT193077 & MT252013 & A. reconditum & N/A & N/A & ..... & ..... & A. reconditum \\
\hline CMT 19 & Cayenne & Pos. & Pos. & Pos. & Pos. & N/A & MN795071 & MT193078 & MT252014 & D. immitis & Pos. & Pos. & MT231954 & C/WDim. & D. immitis \\
\hline CMT 32 & Kourou & Neg. & Pos. & N/A & N/A & N/A &....- &....- &....- &....- & N/A & N/A & ..-... &....- & O-Heartworm \\
\hline CMT 34 & Kourou & Neg. & Neg. & Pos. & Pos. & N/A & MN795072 & MT193079 & MT252015 & D. immitis & N/A & N/A & ..... & .... & D. immitis \\
\hline CMT 36 & Kourou & Neg. & Pos. & N/A & N/A & N/A &.... &....- &....- &.... & N/A & N/A & ..... & ..... & O-Heartworm \\
\hline CMT 38 & Kourou & Neg. & Pos. & Pos. & Pos. & N/A & MN795073 & MT193080 & MT252016 & D. immitis & N/A & N/A & ..... & ..... & D. immitis \\
\hline CMT 40 & Kourou & Pos. & Pos. & Pos. & Pos. & N/A & MN795074 & MT193081 & MT252017 & D. immitis & N/A & N/A & ..... & ..... & D. immitis \\
\hline CMT 41 & Kourou & Neg. & Pos. & Pos. & Pos. & N/A & MN795075 & MT193082 & MT252018 & D. immitis & Pos. & Pos. & MT231955 & C/WDim. & D. immitis \\
\hline CMT 43 & Kourou & Neg. & Neg. & N/A & N/A & N/A &.... & ..... & ..... & ..... & Pos. & N/A & MT231956 & $D / W B r$ & Brugia sp. \\
\hline CMT 52 & Kourou & Neg. & Pos. & Pos. & Pos. & N/A & MN795076 & MT193083 & MT252019 & D. immitis & N/A & N/A & ..... & ..... & D. immitis \\
\hline CMT 53 & Kourou & Neg. & Pos. & N/A & N/A & N/A & .... & .... &.... & .... & N/A & N/A & .... & .... & O-Heartworm \\
\hline CMT 54 & Kourou & Neg. & Pos. & N/A & N/A & N/A & ..... & ..... & ..... & ..... & N/A & N/A & ..... & .... & O-Heartworm \\
\hline CMT 61 & Cayenne & Neg. & Pos. & N/A & N/A & N/A & ..... & ..-.. & .... &.... & N/A & N/A & ..-.. & ..-.. & O-Heartworm \\
\hline CMT 71 & Cayenne & Pos. & Pos. & Pos. & Pos. & N/A & MN795077 & MT193084 & MT252020 & D. immitis & Pos. & Pos. & MT231957 & C/WDim. & D. immitis \\
\hline CMT 75 & Cayenne & Pos. & Pos. & Pos. & Pos. & N/A & MN795078 & MT193085 & MT252021 & D. immitis & Pos. & Pos. & MT231958 & C/WDim. & D. immitis \\
\hline CMT 76 & Cayenne & Neg. & Neg. & Pos. & Pos. & N/A & MN795079 & MT193086 & MT252022 & D. immitis & N/A & N/A &....- & ..-.. & D. immitis \\
\hline CMT 89 & Cayenne & Neg. & Neg. & Pos. & N/A & N/A & MN795085 & ..... & MN795631 & C. bainae & N/A & N/A & ..... & .... & C. bainae \\
\hline CMT 90 & Cayenne & Neg. & Neg. & Pos. & N/A & N/A & MN795086 & ..... & MN795632 & C. bainae & N/A & N/A & ..... & ..... & C. bainae \\
\hline CMT 91 & Cayenne & Pos. & Pos. & Pos. & Pos. & N/A & MN795080 & MT193087 & MT252023 & D. immitis & Pos. & Pos. & MT231959 & C/WDim. & D. immitis \\
\hline CMT 97 & Cayenne & Neg. & Pos. & Pos. & Pos. & N/A & MN795081 & MT193088 & MT252024 & D. immitis & Pos. & Pos. & MT231960 & C/WDim. & D. immitis \\
\hline
\end{tabular}

Neg.: negative, Pos.: positive, N/A: no amplification, AN: Accession number, D. imm: D. immitis, A. rec: A. reconditum, WBr: Wolbachia endosymbiont of Brugia sp., WDim: Wolbachia endosymbiont of D. immitis, O-heartworm: occult heartworm. 
Of those 16 dogs tested positive for filarial DNA, 11 (11.2\%) and $3(3 \%)$ samples were, respectively positive for $D$. immitis and $A$. reconditum by the triplex qPCR. Two samples remained unidentified by this assay. However, the duplex qPCR identified the specific DNA of Wolbachia endosymbiont of D. immitis in $6(6.1 \%)$ samples. These latter were also positive for D. immitis DNA. However, the duplex qPCR did not amplify Wolbachia DNA from 4 samples. Compared to the molecular assays, the heartworm antigens were detected in $9(9.1 \%)$ samples among those positive for D. immitis DNA and in $5(6.1 \%)$ samples negative for $D$. immitis by qPCR. Of these latter, one sample was positive for A. reconditum DNA.

A nearly full-length DNA sequence of the $18 \mathrm{~S}$ rDNA gene (1194 pb) was obtained from all samples tested positive for filarial DNA $(n=16)$. Filarioid single species DNA was obtained from 15 of them. The last one was found co-infected and yielded two amplicon sequences (Table S1).

Four genotypes were identified: 11 sequences of D. immitis (MN795071 to MN795081) were identical each other and showed $100 \%$ identity with D. immitis isolated from dogs in Japan (AB973231), 2 similar sequences of $C$. bainae (MN795085, MN795086) were identical to that isolated from dog in the USA (MH390715), 3 sequences of A. reconditum (MN795082, MN795083, MN795084) were 100\% identical to that isolated from dogs in Côte d'Ivoire (MK495733). Of these, one sequence of Brugia sp. (MN795087) closely related to lymphatic filariasis with 99.9\% identity with Brugia malayi (AF036588) and Wuchereria bancrofti (AY843436).

The cox 1 and $12 S$ sequences were obtained from all D. immitis and A. reconditum previously amplified by the 18S. D. immitis cox1 (MT193078 to MT193088) and 12S (MT252014 to MT252024) sequences were identical to each other for each gene and exhibited $99.78 \%$ and $100 \%$ of identity, respectively with cox1 (MT027229) and 12S (KF707482) sequences of D. immitis isolated from dogs, but were different from the virulent strain of $D$. immitis that occurred in Latin America [39]. This was observed for both cox 1 and 12S, where identity was $91.71 \%$ and $95.12 \%$ with $\operatorname{cox} 1$ (HQ540424) and $12 \mathrm{~S}$ (HQ540423), respectively. However, A. reconditum cox1 (MT193075 to MT193077) and 12S (MT252011 to MT252013) sequences showed an identity of $99.55 \%$ and $100 \%$ of identity with $A$. reconditum cox 1 (JF461456) and 12S (AJ544853) sequences, respectively. The cox1 sequence of Brugia sp. was also amplified (MT193074) and displayed 93.39\% identity with B. timori (AP017686), 92.73\% with B. malayi (MK250713) and 91.19\% with B. pahangi (MK250710). However, the C. bainae 12S sequences (MN795631, MN795631) showed, respectively $97.12 \%$ and $97 \%$ of identity and query cover with C. bainae (KF381408) isolated from dogs in Italy. Despite several attempts, the standard PCRs targeting the cox 1 and the $12 \mathrm{~S}$ rRNA gene failed to amplify the C. bainae and Brugia sp., respectively.

Phylogenetic analyses using ML method of the 18S, cox1 and 12S genes showed that the isolate of both $D$. immitis and A. reconditum from Guiana dogs clustered together with those usually isolated around the world (Figures 2-4). Moreover, both cox 1 and $12 S$ trees (Figures 3 and 4) indicate that D. immitis isolate is distinguished by a clearly separated branch from the virulent isolate from Brazil [39]. The isolate of Brugia sp. was clustered with brugian species and was a clearly separated branch although it was placed in the same genus. This was observed for both $18 \mathrm{~S}$ (Figure 2) and cox 1 inferences (Figure 3). While C. bainae isolates were clustered with the same species isolated from dogs in the USA (Figure 2). However, the $12 \mathrm{~S}$ tree showed its separation from the isolated one in Europe (Figure 4). 


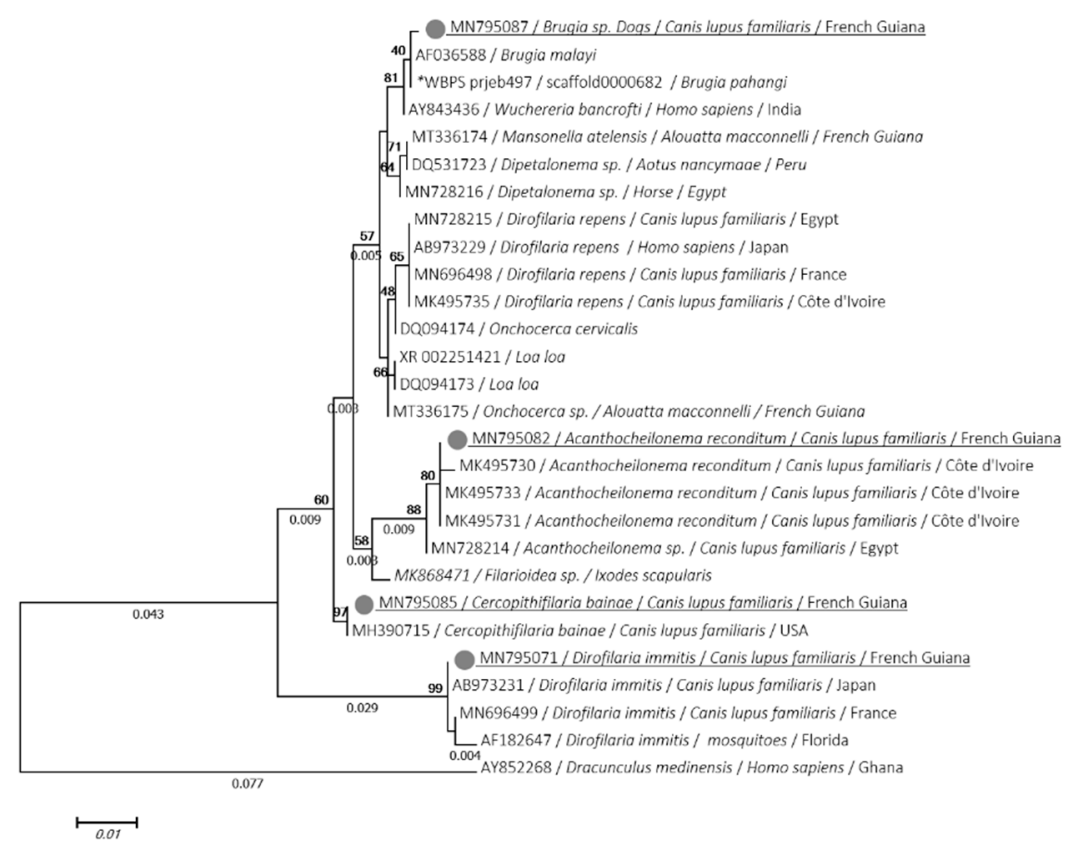

Figure 2. Phylogram of the $18 \mathrm{~S}$ rRNA gene generated by maximum likelihood method from 28 partial (969) sequences. The tree with the highest log likelihood $(-2078,7662)$ is shown. A discrete gamma distribution was used to model evolutionary rate differences among sites $(5$ categories $(+\mathrm{G}$, parameter $=$ 01254)). Numbers above and below branches are the display of bootstrap replicate values and branches length, respectively. Host, geographical location (when available) and GenBank accession number are indicated in each node. The sequences of the present study are underlined. *: indicates DNA sequences retrieved from Worm database.

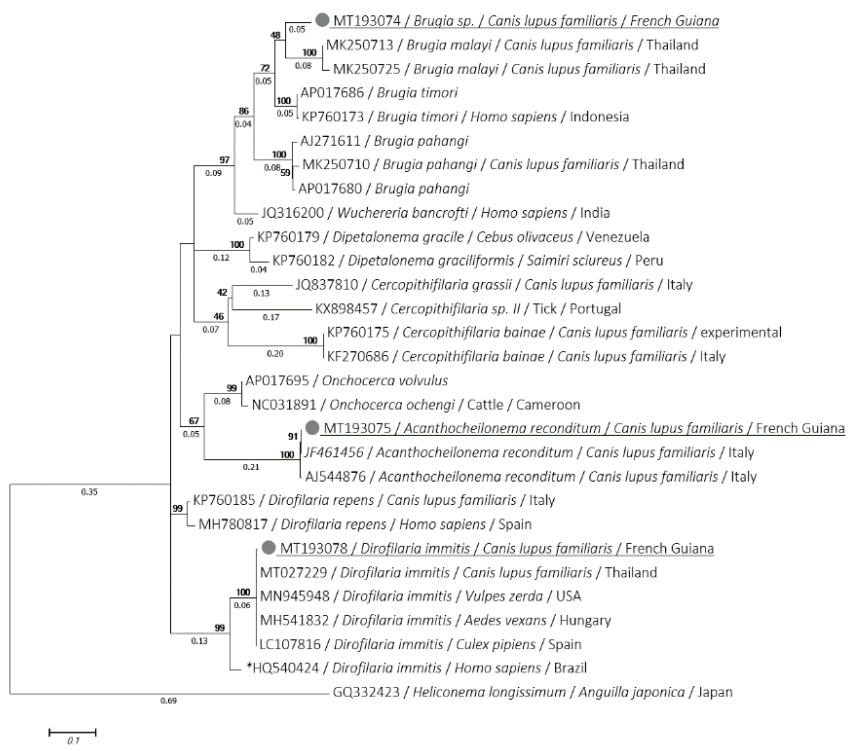

Figure 3. Phylogram of the cox 1 gene generated by maximum likelihood method from 29 partial (449) sequences. The tree with the highest log likelihood (-2690.9892) is shown. A discrete Gamma distribution was used to model evolutionary rate differences among sites $(5$ categories $(+G$, parameter $=0.4403)$ ). Numbers above and below branches are the display of bootstrap replicate values and branches length, respectively. Host, geographical location (when available) and GenBank accession number are indicated in each node. The sequences of the present study are underlined. *: indicates the most virulent strain of D. immitis from Latin America [39]. 


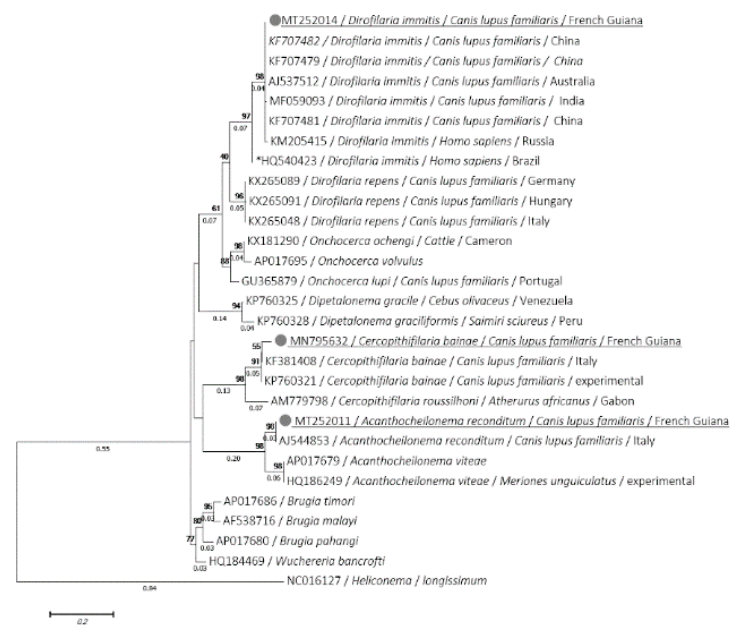

Figure 4. Phylogram of the $12 \mathrm{~S}$ rRNA gene generated by maximum likelihood method from 29 partial (421) sequences. The tree with the highest log likelihood 5-2356.1682) is shown. A discrete Gamma distribution was used to model evolutionary rate differences among sites $(5$ categories $(+G$, parameter $=0.6437)$ ). Numbers above and below branches are the display of bootstrap replicate values and branches length, respectively. Host, geographical location (when available) and GenBank accession number are indicated in each node. The sequences of the present study are underlined. *: indicates the most virulent strain of D. immitis from Latin America [39].

Wolbachia 16S partial sequences were successfully amplified and sequenced from all samples detected by qPCR. A total of 10 samples were amplified and were split into two distinct genotypes according to the BLAST results. Six identical sequences (MT231954, MT231955, MT231957, MT231958, MT231959, MT231960) showed an identity ranging from $99.3 \%$ to $99.6 \%$ with Wolbachia endosymbiont of D. immitis (MH062176, AF088187). These latter were isolated from samples positive for D. immitis single-specie-DNA. While three sequences were isolated from samples tested negative for filarial DNA and another one was obtained from a co-infected sample by A. reconditum and Brugia sp. All were identical to each other (MT231951, MT231952, MT231953, MT231956) and displayed 100\% identity with the Wolbachia endosymbiont of B. malayi (CP034333), B. pahangi (AJ012646) and B. timori (AJ012646). The phylogenetic inference classified these genotypes into the clade $C$ and D supergroups of Wolbachia and were clustered with Wolbachia endosymbiont of D. immitis and Brugia spp., respectively (Figure 5).

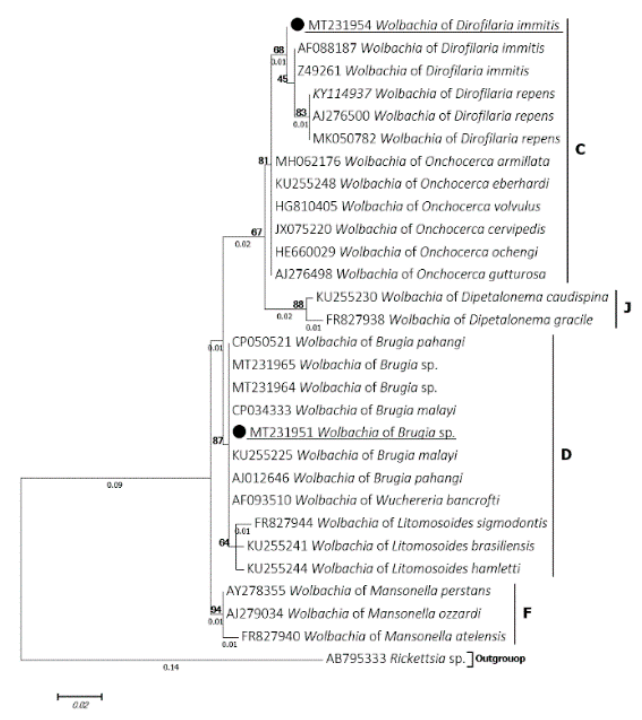

Figure 5. Phylogram of the Wolbachia 16S gene generated by maximum likelihood method from 
29 partial (295) sequences. The tree with the highest log likelihood (-735.8600) is shown. A discrete Gamma distribution was used to model evolutionary rate differences among sites ( 5 categories $(+G$, parameter $=0.2679)$ ). Numbers above and below branches are the display of bootstrap replicate values and branches length, respectively. Host, geographical location (when available) and GenBank accession number are indicated in each node. The sequences of the present study are underlined (black circle).

\section{Discussion}

This is the first molecular report of filaria and Wolbachia infections from dogs in French Guiana. Dogs are the most implicated reservoir for filariasis $[9-11,15,17,19]$. The control of these vector-borne helminths is based on epidemiological information and the use of adequate diagnostic methods [40]. The present study highlighted the presence of four filarial species in Guiana's dogs: D. immitis, A. reconditum and for the first time C. bainae and Brugia sp. Compared to the parasitological assays, the molecular diagnosis remains the most adequate tool to study the diversity of these parasites [28]. This tool had gained an important increase in research area [41,42]. In addition, several studies have recently associated the molecular detection of Wolbachia in the diagnosis of canine filariasis $[9,10,27]$.

Despite the several diagnostic assays we performed, our results remained not exhaustive and are limited by the sampling method. In the absence of skin samples, we are not able to achieve the exploration of filarial infections from Guiana's dogs, especially those with cutaneous microfilariae, such as Onchocerca lupi and Cercopithifilaria spp. [17].

Microfilariae were not found in the blood samples of twelve dogs that tested positive for filarial DNA. The blood wet mount preparation is not a microfilariae concentration test, and only detects an integral microfilariae with a threshold of 30 microfilaria (mf)/mL [43,44]. Due to the lack of an adequate equipment in the field we were not able to perform a microfilariae concentration tests, such as Knott or filtration tests [45]. This represents a limitation of this study, which decrease the accuracy of our results in terms of sensitivity and specificity. Likewise, the molecular assays are able to detect the DNA from a micro-fragment of microfilaria with an analytical sensitivity threshold of $1.5 \times 10^{-4} \mathrm{mf} / \mathrm{mL}$ [27].

It is worth highlighting that $D$. immitis infection is the most diagnosed canine filariasis in the world. In French Guiana, this parasite is known to be enzootic, as veterinarians often prescribe chemoprophylaxis. However, epidemiological data are lacking. The D. immitis infection rate of $16.3 \%$ $(n=98)$ reported here is complementary to a study carried out in Guyana using the Knott's test $(14.1 \%, n=2135)$ [46] and elsewhere in Venezuela $(15.2 \%, n=138)$ and in Dominican Republic $(18.2 \%$, $n=104)[46,47]$.

In the field as in veterinary clinics, heartworm antigens tests are the most widely used assays. These tests detect the adult antigens of $D$. immitis from both occult and non-occult infections with different levels of sensitivity and specificity [48]. Here, the WITNESS ${ }^{\circledR}$ Dirofilaria test revealed the presence of $D$. immitis antigens in 15 dogs, five of which were considered as an occult infection. Of these, one sample was also found positive for A. reconditum DNA. Despite the fact that this filarioid may cross-react on heartworm antigen tests [49], the occult infection cannot be excluded. In Latin America, A. reconditum and D. immitis are often present as co-infections in dogs [28]. Furthermore, the presence of Spirocerca lupi in Guiana dogs [50] could interfere with heartworm antigen and produce such results [41]. On the other hand, no antigens were detected from two D. immitis DNA-positive samples (CMT-34, CMT76) (Table 2). This could be related the presence of immune-complex that block the antigen detection process or to the low secretion of antigens by adults worms [8].

To the best of our knowledge, no human infection by D. immitis has been reported in French Guiana to date. Since humans can be infected, doctors could be confronted with this parasitosis, which is mainly characterized by the presence of pulmonary nodules. In South America, fifty sporadic cases have been reported: pulmonary (Venezuela, Colombia, Brazil, Argentina) and subcutaneous/ocular nodules (Brazil, Chile) [8,51,52]. D. immitis implicated in human ocular dirofilariasis was classified as a more virulent strain [51]. Fortunately, the phylogenetic analysis we conducted indicated that it is not the virulent $D$. immitis (Figures 3 and 4 ) which could explain the lower prevalence of human cases [39]. 
It is not surprising that no dog was found parasitized by D. repens responsible for subcutaneous dirofilariasis [34]. This benign, but more zoonotic dirofilariasis is only described in the Old World. In America, a few doubtful cases of D. repens were reported [53-55] wherein a lack of information was provided on the origin of the dogs examined. The possibility that this is an imported case cannot be ruled out.

A. reconditum is the causative agent of canine subcutaneous filariasis [15]. This affection, characterized by subcutaneous nodules, is largely neglected as it usually remains unnoticed with no clinical consequences The infection has a worldwide distribution, including the United States, South America, Oceania and many African and European countries [15]. Human infections by A. reconditum are quite exceptional. One case (subconjunctival infection) has been described in Australia [36] and two cases in Turkey [56].

Surprisingly, we found the DNA of C. bainae in the blood of two dogs. This filarioid was first described in Brazil and has since been reported in Europe, Africa, Australia and Americas [57]. The adult form of these tick-borne filaroids usually dwell beneath the cutaneous tissues of infected dogs, while their microfilaria are distributed unevenly in superficial dermal tissues [58]. Our study constitutes the first report of its DNA in blood. The study conducted by Rojas et. al. (2015), reported the presence of a filarioid DNA from the blood, wherein a low-quality inclusive DNA sequence of a dermal filarioid was detected using the HRM real time qPCR. The same dog was skin-positive for C. bainae DNA [57]. These results are not exhaustive and further investigation of this filarioid from skin samples are needed to describe the real prevalence of this filariasis. In addition, our results are complementary to the phylogenetic analysis of C. bainae carried out on isolates from Brazil, which revealed the evolutionary separation of isolates from Europe and Latin America [59].

Another surprising finding was the detection of a filarioid species from the genus Brugia. Canine brugian infections are often caused by Brugia species associated with lymphatic filariasis in Asia (B. malayi, B. pahangi and B. timori) [12]. While the other brugian infections are encountered in wild animals, such as the Asian primates, raccoons and rabbits in the USA [60]. Recently, in Brazil, blood microfilaria from the genus Brugia were reported from the ring-tailed coatis (Nasua nasua) [61]. In Guiana, the unique species of Brugia was described morphologically from the lymphatic system of the coatimundi (Nasua nasua vittata) and was named Brugia guyanensis (Orihel 1964) [62]. The possibility that the Brugia sp. herein we detected is the same B. guyanensis cannot be ruled out in the absence of morphologic identification. Our findings highlighted the circulation of a potential zoonotic Brugia in French Guiana dogs. In addition, human health could be at risk if the nematode reported here in domestic dogs had zoonotic potential.

Finally, our results reported the presence of two Wolbachia strains from the clade C and D of filarial nematodes, wherein the first one was clustered with those associated with $D$. immitis and the second one with those of lymphatic filarial parasites. In terms of host-relationship, Wolbachia strain is filaria species-specific [23], which allows them to serve as a diagnostic target $[10,24,45]$. Moreover, in heartworm infected dogs and cats, these bacteria are implemented in pulmonary disease [24,25]. Clarifying these bacteria by antibiotic treatments induces infertility and death of filarioid worms and has reduced the incidence of inflammatory pulmonary lesions and thrombi associated with heartworm disease, providing an effective treatment strategy for the control and eradication of the filarial infection in human and dogs [22,26].

\section{Conclusions}

The present study molecularly detected D. immitis, A. reconditum, C. bainae and Brugia sp. and the associated Wolbachia endosymbionts from canine blood in French Guiana. Brugia sp. and C. bainae were detected for the first time in French Guiana dogs. It would be interesting to know whether Brugia sp. DNA we detected corresponds to a new species or if it is Brugia guyanensis. To this end, a morphologic based-taxonomy should be investigated simultaneously with molecular studies in the future. In addition, further studies based on blood and skin samples are required to expand the 
epidemiological knowledge of these nematodes in French Guiana. Finally, there is an urgent need for the implementation of preventive chemoprophylaxis against these vector-borne helminths. The use of the anti-Wolbachia drugs should also be explored in the future.

Supplementary Materials: The following are available online at http://www.mdpi.com/2076-2607/8/5/770/s1, Table S1: PCR/Sequencing results of the $18 \mathrm{~S}$.

Author Contributions: Y.L., D.T., J.-L.M. and B.D.: conceptualization, methodology; Y.L. and D.T.: formal analysis; J.-L.M., S.W.-G. and B.D.: field investigations; Y.L., D.T., B.D., O.M.: writing-review and editing. All authors have read and agreed to the published version of the manuscript.

Funding: This study was supported by the French Armed Forces Health Service, the "Association pour la Recherche en Infectiologie", Ceva Santé Animale company and the Institut Hospitalo-Universitaire Méditerranée Infection, the National Research Agency under the program "Investissements d'avenir", reference ANR-10-IAHU-03, the Région Provence-Alpes-Côte d'Azur and European funding FEDER PRIMI.

Acknowledgments: We thank Christophe Calleja (Zoetis) for supply of serologic kits.

Conflicts of Interest: The authors declare no conflict of interest.

\section{References}

1. Dantas-Torres, F. Canine vector-borne diseases in Brazil. Parasit. Vectors 2008, 1, 25. [CrossRef] [PubMed]

2. Otranto, D.; Dantas-Torres, F.; Breitschwerdt, E.B. Managing canine vector-borne diseases of zoonotic concern: Part one. Trends Parasitol. 2009, 25, 157-163. [CrossRef] [PubMed]

3. Medkour, H.; Davoust, B.; Dulieu, F.; Maurizi, L.; Lamour, T.; Marié, J.-L.; Mediannikov, O. Potential animal reservoirs (dogs and bats) of human visceral leishmaniasis due to Leishmania infantum in French Guiana. PLoS Negl. Trop. Dis. 2019, 13, e0007456. [CrossRef] [PubMed]

4. Dahmani, M.; Marié, J.-L.; Mediannikov, O.; Raoult, D.; Davoust, B. First Identification of Anaplasma platys in the blood of dogs from French Guiana. Vector Borne Zoonotic Dis. 2015, 15, 170-172. [CrossRef] [PubMed]

5. Tahir, D.; Davoust, B.; Heu, K.; Lamour, T.; Demar, M.; Marié, J.-L.; Blanchet, D. Molecular and serological investigation of Trypanosoma cruzi infection in dogs in French Guiana. Vet. Parasitol. Reg. Stud. Rep. 2017, 12, 106-109. [CrossRef] [PubMed]

6. Davoust, B.; Keundjian, A.; Rous, V.; Maurizi, L.; Parzy, D. Validation of chemoprevention of canine monocytic ehrlichiosis with doxycycline. Vet. Microbiol. 2005, 107, 279-283. [CrossRef] [PubMed]

7. Llagonne-Barets, M.; Icard, V.; Leparc-Goffart, I.; Prat, C.; Perpoint, T.; Andre, P.; Ramière, C. A case of Mayaro virus infection imported from French Guiana. J. Clin. Virol. 2016, 77, 66-68. [CrossRef]

8. Simón, F.; Siles-Lucas, M.; Morchón, R.; González-Miguel, J.; Mellado, I.; Carretón, E.; Montoya-Alonso, J.A. Human and animal dirofilariasis: The emergence of a zoonotic mosaic. Clin. Microbiol. Rev. 2012, 25, 507-544. [CrossRef]

9. Laidoudi, Y.; Ringot, D.; Watier-Grillot, S.; Davoust, B.; Mediannikov, O. A cardiac and subcutaneous canine dirofilariosis outbreak in a kennel in central France. Parasite 2019, 26, 72. [CrossRef]

10. Satjawongvanit, H.; Phumee, A.; Tiawsirisup, S.; Sungpradit, S.; Brownell, N.; Siriyasatien, P.; Preativatanyou, K. Molecular analysis of canine filaria and its Wolbachia endosymbionts in domestic dogs collected from two animal university hospitals in Bangkok Metropolitan Region, Thailand. Pathogens 2019, 8, 114. [CrossRef]

11. Ambily, V.; Pillai, U.N.; Arun, R.; Pramod, S.; Jayakumar, K. Detection of human filarial parasite Brugia malayi in dogs by histochemical staining and molecular techniques. Vet. Parasitol. 2011, 181, 210-214. [CrossRef] [PubMed]

12. Ravindran, R.; Varghese, S.; Nair, S.N.; Balan, V.M.; Lakshmanan, B.; Ashruf, R.M.; Kumar, S.S.; Gopalan, A.K.K.; Nair, A.S.; Malayil, A.; et al. Canine filarial infections in a human Brugia malayi endemic area of India. BioMed Res. Int. 2014, 2014, 1-9. [CrossRef] [PubMed]

13. Drake, J.; Wiseman, S. Increasing incidence of Dirofilaria immitis in dogs in USA with focus on the southeast region 2013-2016. Parasit. Vectors 2018, 11, 39. [CrossRef] [PubMed]

14. World Health Organization. Lymphatic Filariasis. Available online: https://www.who.int/news-room/factsheets/detail/lymphatic-filariasis (accessed on 12 May 2020). 
15. Brianti, E.; Gaglio, G.; Napoli, E.; Giannetto, S.; Dantas-Torres, F.; Bain, O.; Otranto, D. New insights into the ecology and biology of Acanthocheilonema reconditum (Grassi, 1889) causing canine subcutaneous filariosis. Parasitology 2012, 139, 530-536. [CrossRef]

16. Otranto, D.; Brianti, E.; Latrofa, M.S.; Annoscia, G.; Weigl, S.; Lia, R.P.; Gaglio, G.; Napoli, E.; Giannetto, S.; Papadopoulos, E.; et al. On a Cercopithifilaria sp. transmitted by Rhipicephalus sanguineus: A neglected, but widespread filarioid of dogs. Parasit. Vectors 2012, 5, 1. [CrossRef]

17. Cortes, H.; Cardoso, L.; Giannelli, A.; Latrofa, M.S.; Dantas-Torres, F.; Otranto, D. Diversity of Cercopithifilaria species in dogs from Portugal. Parasit. Vectors 2014, 7, 261. [CrossRef]

18. Nelson, G.S. Dipetalonema reconditum (Grassi, 1889) from the dog with a note on its development in the flea, Ctenocephalides felis and the louse, Heterodoxus spiniger. J. Helminthol. 1962, 36, 297. [CrossRef]

19. Muñoz, C.; Gonzálvez, M.; Rojas, A.; Martínez-Carrasco, C.; Baneth, G.; Berriatua, E.; Ortiz, J. Massive microfilaremia in a dog subclinically infected with Acanthocheilonema dracunculoides. Parasitol. Int. 2020, 76, 102070. [CrossRef]

20. Franchini, D.; Giannelli, A.; Di Paola, G.; Cortes, H.; Cardoso, L.; Lia, R.P.; Campbell, B.; Dantas-Torres, F.; Lenoci, D.; Abu Assad, E.; et al. Image diagnosis of zoonotic onchocercosis by Onchocerca lupi. Vet. Parasitol. 2014, 203, 91-95. [CrossRef]

21. Martin, C.; Gavotte, L. The bacteria Wolbachia in filariae, a biological Russian dolls' system: New trends in antifilarial treatments. Parasite 2010, 17, 79-89. [CrossRef]

22. Sabūnas, V.; Radzijevskaja, J.; Sakalauskas, P.; Petkevicius, S.; Karvelienė, B.; Žiliukienė, J.; Lipatova, I.; Paulauskas, A. Dirofilaria repens in dogs and humans in Lithuania. Parasit. Vectors 2019, 12, 177. [CrossRef] [PubMed]

23. Bandi, C.; Anderson, T.J.C.; Genchi, C.; Blaxter, M. Phylogeny of Wolbachia in filarial nematodes. Proc. R. Soc. B Boil. Sci. 1998, 265, 2407-2413. [CrossRef] [PubMed]

24. Turba, M.E.; Zambon, E.; Zannoni, A.; Russo, S.; Gentilini, F. Detection of Wolbachia DNA in blood for diagnosing filaria-associated syndromes in cats. J. Clin. Microbiol. 2012, 50, 2624-2630. [CrossRef] [PubMed]

25. Dingman, P.; Levy, J.K.; Kramer, L.H.; Johnson, C.M.; Lappin, M.R.; Greiner, E.C.; Courtney, C.H.; Tucker, S.J.; Morchón, R. Association of Wolbachia with heartworm disease in cats and dogs. Vet. Parasitol. 2010, 170, 50-60. [CrossRef]

26. Maia, C.; Altet, L.; Serrano, L.; Cristóvão, J.; Tabar, M.-D.; Francino, O.; Cardoso, L.; Campino, L.; Roura, X. Molecular detection of Leishmania infantum, filariae and Wolbachia spp. in dogs from southern Portugal. Parasit. Vectors 2016, 9, 170. [CrossRef]

27. Laidoudi, Y.; Davoust, B.; Varloud, M.; El Hadj, A.N.; Fenollar, F.; Mediannikov, O. Development of a multiplexed qPCRs-based approach for the diagnosis of Dirofilaria immitis, D. repens, Acanthocheilonema reconditum and the others filariosis. BioRxiv 2019, 24, 842575. [CrossRef]

28. De Argôlo, E.G.G.; Reis, T.; Fontes, D.A.T.; Gonçalves, E.C.; Giese, E.G.; Melo, F.T.V.; Dos Santos, J.N.; Furtado, A.P. Canine filariasis in the Amazon: Species diversity and epidemiology of these emergent and neglected zoonoses. PLoS ONE 2018, 13, e0200419. [CrossRef]

29. Schneider, M.C.; Aguilera, X.; Junior, J.B.D.S.; Ault, S.K.; Najera, P.; Martínez, J.; Requejo, R.; Nicholls, R.S.; Yadon, Z.E.; Silva, J.C.; et al. Elimination of neglected diseases in Latin America and the Caribbean: A mapping of selected diseases. PLoS Negl. Trop. Dis. 2011, 5, e964. [CrossRef]

30. Werren, J.H.; Windsor, D.M. Wolbachia infection frequencies in insects: Evidence of a global equilibrium? Proc. R. Soc. B Boil. Sci. 2000, 267, 1277-1285. [CrossRef]

31. Song, H.; Buhay, J.E.; Whiting, M.F.; Crandall, K.A. Many species in one: DNA barcoding overestimates the number of species when nuclear mitochondrial pseudogenes are coamplified. Proc. Natl. Acad. Sci. USA 2008, 105, 13486-13491. [CrossRef]

32. Altschul, S.F.; Gish, W.; Miller, W.; Myers, E.W.; Lipman, D.J. Basic local alignment search tool. J. Mol. Biol. 1990, 215, 403-410. [CrossRef]

33. Howe, K.L.; Bolt, B.J.; Shafie, M.; Kersey, P.; Berriman, M. WormBase ParaSite-A comprehensive resource for helminth genomics. Mol. Biochem. Parasitol. 2017, 215, 2-10. [CrossRef] [PubMed]

34. Hall, T.; Biosciences, I.; Carlsbad, C. BioEdit: An important software for molecular biology. GERF Bull. Biosci. 2011, 2, 60-61.

35. Tamura, K.; Stecher, G.; Peterson, D.; Filipski, A.; Kumar, S. MEGA6: Molecular Evolutionary Genetics Analysis Version 6.0. Mol. Boil. Evol. 2013, 30, 2725-2729. [CrossRef] 
36. Kimura, M. A simple method for estimating evolutionary rates of base substitutions through comparative studies of nucleotide sequences. J. Mol. Evol. 1980, 16, 111-120. [CrossRef]

37. Nei, M.; Kumar, S. Molecular Evolution and Phylogenetics; Oxford University Press: New York, NY, USA, 2000; p. 333.

38. Hasegawa, M.; Kishino, H.; Yano, T. aki Dating of the human-ape splitting by a molecular clock of mitochondrial DNA. J. Mol. Evol. 1985, 22, 160-174. [CrossRef]

39. Dantas-Torres, F.; Otranto, D. Dirofilariosis in the Americas: A more virulent Dirofilaria immitis? Parasit. Vectors 2013, 6, 288. [CrossRef]

40. Otranto, D.; Dantas-Torres, F.; Breitschwerdt, E. Managing canine vector-borne diseases of zoonotic concern: Part two. Trends Parasitol. 2009, 25, 228-235. [CrossRef]

41. Aroch, I.; Rojas, A.; Slon, P.; Lavy, E.; Segev, G.; Baneth, G. Serological cross-reactivity of three commercial in-house immunoassays for detection of Dirofilaria immitis antigens with Spirocerca lupi in dogs with benign esophageal spirocercosis. Vet. Parasitol. 2015, 211, 303-305. [CrossRef]

42. Mallawarachchi, C.H.; Chandrasena, N.T.G.A.; Wickramasinghe, S.; Premaratna, R.; Gunawardane, N.Y.I.S.; Mallawarachchi, N.S.M.S.M.; De Silva, N.R. A preliminary survey of filarial parasites in dogs and cats in Sri Lanka. PLoS ONE 2018, 13, e0206633. [CrossRef]

43. Bowman, D.D.; Mannella, C. Macrocyclic lactones and Dirofilaria immitis microfilariae. Top. Companion Anim. Med. 2011, 26, 160-172. [CrossRef] [PubMed]

44. Rossi, M.I.D.; Paiva, J.; Bendas, A.; Mendes-De-Almeida, F.; Knackfuss, F.; Miranda, M.; Guerrero, J.; Fernandes, O.; Labarthe, N.V. Effects of doxycycline on the endosymbiont Wolbachia in Dirofilaria immitis (Leidy, 1856)—Naturally infected dogs. Vet. Parasitol. 2010, 174, 119-123. [CrossRef] [PubMed]

45. Evans, C.C.; Bradner, J.L.; Savadelis, M.D.; Nelson, C.T.; Moorhead, A.R. Acetic acid as an alternative reagent in the modified Knott test. Vet. Parasitol. 2019, 276, 108975. [CrossRef]

46. Orihal, T.C. Canine filariasis in British Guiana. J. Parasitol. 1964, 50, 33.

47. Guilarte, D.V.; Martínez, E.G.; El Hen, F.; Guzmán, R.; Blondell, D.; Díaz, M.T.; Santiago, J. Diagnóstico de Dirofilaria immitis en el municipio Sucre, estado Sucre, Venezuela. Bol. Mal. Salud Amb. 2011, 51, 51-58.

48. Duran-Struuck, R.; Jost, C.; Hernandez, A.H. Dirofilaria immitis prevalence in a canine population in the Samana Peninsula (Dominican Republic)—June 2001. Vet. Parasitol. 2005, 133, 323-327. [CrossRef]

49. Gillis, J.M.; Smith, R.D.; Todd, K.S. Diagnostic criteria for an enzyme-linked immunosorbent assay for occult heartworm disease: Standardization of the test system in naturally exposed dogs. Am. J. Veter Res. 1984, $45,2289-2292$.

50. Bartolo, A. La spirocercose canine à Spirocerca lupi. Point Vét. 2006, 269, 20-26.

51. Bain, O.; Otranto, D.; Diniz, D.; Dos Santos, J.N.; De Oliveira, N.P.; Almeida, I.; De Almeida, R.N.F.; De Almeida, L.N.F.; Dantas-Torres, F.; Sobrinho, E.F.D.A. Human intraocular filariasis caused by Pelecitus sp. Nematode, Brazil. Emerg. Infect. Dis. 2011, 17, 867-869. [CrossRef]

52. Mar, P.-H.; Yang, I.-C.; Chang, G.-N.; Fei, C.-Y. Specific polymerase chain reaction for differential diagnosis of Dirofilaria immitis and Dipetalonema reconditum using primers derived from internal transcribed spacer region 2 (ITS2). Vet. Parasitol. 2002, 106, 243-252. [CrossRef]

53. López, J.; Valiente-Echeverría, F.; Carrasco, M.; Mercado, R.; Abarca Villaseca, K. Morphological and molecular identification of canine filariae in a semi-rural district of the Metropolitan Region in Chile. Rev. Chil. Infectol. 2012, 29, 284-289. [CrossRef] [PubMed]

54. Ramos-Lopez, S.; León-Galván, M.F.; Salas-Alatorre, M.; Lechuga-Arana, A.A.; Valencia-Posadas, M.; Gutiérrez-Chávez, A.J. First molecular identification of Dirofilaria repens in a dog blood sample from Guanajuato, Mexico. Vector Borne Zoonotic Dis. 2016, 16, 734-736. [CrossRef] [PubMed]

55. Lent, H.; De Freitas, J.F.T. Dirofilariose sub-cutanea dos cães no Brasil. Memórias Inst. Oswaldo Cruz 1937, 32, 443-448. [CrossRef]

56. Huynh, T.; Thean, J.; Maini, R. Dipetalonema reconditum in the human eye. Br. J. Ophthalmol. 2001, 85, 1391-1392. [CrossRef]

57. Rojas, A.; Rojas, D.; Montenegro, V.M.; Baneth, G. Detection of Dirofilaria immitis and other arthropod-borne filarioids by an HRM real-time qPCR, blood-concentrating techniques and a serological assay in dogs from Costa Rica. Parasit. Vectors 2015, 8, 170. [CrossRef] 
58. Otranto, D.; Brianti, E.; Abramo, F.; Gaglio, G.; Napoli, E.; Latrofa, M.S.; Ramos, R.A.; Dantas-Torres, F.; Bain, O. Cutaneous distribution and localization of Cercopithifilaria sp. microfilariae in dogs. Vet. Parasitol. 2012, 190, 143-150. [CrossRef]

59. Ramos, R.A.N.; Rêgo, A.G.D.O.D.; Firmino, E.D.D.F.; Ramos, C.A.D.N.; De Carvalho, G.A.; Dantas-Torres, F.; Otranto, D.; Alves, L.C. Filarioids infecting dogs in northeastern Brazil. Vet. Parasitol. 2016, 226, $26-29$. [CrossRef]

60. Paniz-Mondolfi, A.E.; Gárate, T.; Stavropoulos, C.; Fan, W.; González, L.M.; Eberhard, M.; Kimmelstiel, F.; Sordillo, E.M. Zoonotic filariasis caused by novel Brugia sp. nematode, United States, 2011. Emerg. Infect. Dis. 2014, 20, 1248-1250. [CrossRef]

61. Moraes, M.F.D.; Da Silva, M.X.; Magalhães-Matos, P.C.; Albuquerque, A.C.A.; Tebaldi, J.H.; Mathias, L.A.; Hoppe, E.G.L. Filarial nematodes with zoonotic potential in ring-tailed coatis (Nasua nasua Linnaeus, 1766, Carnivora: Procyonidae) and domestic dogs from Iguaçu National Park, Brazil. Vet. Parasitol. Reg. Stud. Rep. 2017, 8, 1-9. [CrossRef]

62. Orihel, T.C. Brugia guyanensis sp. n. (Nematoda: Filarioidea) from the Coatimundi (Nasua nasua vittata) in British Guiana. J. Parasitol. 1964, 50, 115. [CrossRef]

(C) 2020 by the authors. Licensee MDPI, Basel, Switzerland. This article is an open access article distributed under the terms and conditions of the Creative Commons Attribution (CC BY) license (http://creativecommons.org/licenses/by/4.0/). 